\title{
Citronella Oil
}

National Cancer Institute

\section{Source}

National Cancer Institute. Citronella Oil. NCI Thesaurus. Code C71856.

The essential oil extracted from the leaves and stems of various Cymbopogon species.

Citronella oil is used for its aromatic properties in parfumary, cosmetics, candles and soaps, and as an insect repellant. 